\title{
New parameters describing morphological variations in the suprascapular notch region as potential predictors of suprascapular nerve entrapment
}

\author{
Michał Podgórski ${ }^{1}$, Mirosław Topol ${ }^{2}$, Marcin Sibiński ${ }^{3}$, Piotr Grzelak ${ }^{4}$, Ludomir Stefańczyk ${ }^{4}$ and Michał Polguj ${ }^{*}$
}

\begin{abstract}
Background: The suprascapular notch (SSN), bridged by the superior transverse scapular ligament (STSL), creates a pathway for the suprascapular nerve (SN). Morphological variations in the SSN region are common and can increase the risk of neuropathy by constricting the space for the nerve. The aim of this study was to establish new objective parameters that take this complex morphology into account.

Methods: The SSN region of 100 formalin-fixed cadaveric shoulders was dissected. The dimensions of the SSN, the STSL and the anterior coracoscapular ligament (ACSL), as well as diameters of the SN, associated vessels and SN passage area, were measured by means of quantitative visual data analysis software to assign those structures to present classifications. The area reduction coefficient (ARC) and the ambit occupation coefficient (AOC) were defined and calculated for each shoulder.

Results: The mean $A R C$ and $A O C$ for ligaments in the suprascapular region were: $A_{R C} C_{S L L}=71.6 \%, A R C_{A C S L}=9.6 \%$, $\mathrm{AOC}_{\text {STSL }}=56.8 \%$ and $\mathrm{AOC}_{\mathrm{ACSL}}=9.1 \%$. The SN passage area, ARC and AOC did not differ significantly between SSN types. The SN passage area and ARC differed significantly between band- and fan-shaped types of STSL. A significant relationship was observed between $A R C$ and $A O C(R=0.6855 ; p<0.0001)$. The $S N$ passage area correlated significantly with $A R C(R=-0.7555 ; p<0.0001)$ and $A O C(R=-0.5609 ; p<0.0001)$.

Conclusions: The proposed parameters convey the complex morphology of the SSN region in a quantitative manner. The area reduction coefficient seems to be a more relevant indicator than the AOC as it better correlates with the SN passage area. Contrary to the SSN type, the STSL type significantly influences SN passage area and ARC.
\end{abstract}

Keywords: Suprascapular nerve entrapment, Superior transverse scapular ligament, Suprascapular notch, Suprascapular foramen

\section{Background}

The suprascapular nerve originates predominantly from the ventral rami of the C5 and C6 nerve roots, and after separation from the upper trunk of brachial plexus passes above the upper border of the scapula through an osteo-fibrous tunnel comprising the suprascapular notch (SSN) bridged by the superior traverse scapular ligament (STSL) [1]. It typically travels with the suprascapular

\footnotetext{
*Correspondence: michal.polguj@umed.lodz.pl

'Department of Angiology, Chair of Anatomy, Medical University of Łódź,

Narutowicza 60, Łódź 90-136, Poland

Full list of author information is available at the end of the article
}

vein [1]. The associated artery runs above the STSL [1]. The suprascapular nerve innervates the supraspinatus and infraspinatus muscles and also supports sensory branches to the posterior side of the glenohumeral joint capsule and up to $70 \%$ of skin of the shoulder [2]. Compression or injury to the $\mathrm{SN}$ can result in SN entrapment syndrome, which was first described in 1936 by André Thomas [3].

Many anatomical variations of the SSN region make it a very heterogeneous structure. The shapes of the SSN and the STSL are highly diverse [4-7], as is the occurrence of 
the anterior coracoscapular ligament (ACSL), which is reported with a frequency ranging from $18.8 \%$ [5] to $60 \%$ [8]. A tight and narrow SSN or a broad, bifid or ossified STSL/ACSL can obstruct the SN passage, increasing the risk of its irritation, which may eventually lead to the development of proximal SN entrapment syndrome [2].

The aim of this study is to establish the parameters that relate to reductions in $\mathrm{SN}$ passage area and which also take into account the constellation of anatomical variations in the SSN region. Those new parameters may assist quantitative evaluation of the risk of SN neuropathy.

\section{Methods}

The suprascapular notches of 100 formalin-fixed, cadaveric shoulders (41 left and 59 right) were dissected. All shoulders originated from the Polish population. All donors gave informed consent for their bodies to be used for scientific purposes. Ethical approval to undertake this study was obtained from the Bioethics Commission of the Medical University of Lodz (protocol no. RNN/580/13/KE).

The arrangement of the $\mathrm{SN}$ and vessels in relation to the STSL was identified. Photographic documentation of structures in the SSN region was obtained. Quantitative image analysis software (MultiScanBase 18.03 software, Computer Scanning System II, Warsaw, Poland) was used to measure the length of the STSL, as well as its proximal and distal width, as well as the maximal depth, superior and middle transverse diameters of the SSN, as described by Polguj et al. [6].

The SSN and STSL were classified into different types according to newest classifications for both of these structures [6,9]. The SN passage area and the STSL area were evaluated. When present, the area of the ACSL was also evaluated, together with the area of the opening below it.

Based on the photographic documentation analysis, two new parameters were defined and described as follows (Figures 1 and 2):

1. The area reduction coefficient (ARC), calculated according to the following formula (Figure 1):

$$
\begin{aligned}
& \mathrm{ARC}[\%]=\mathrm{ARC}_{\mathrm{STSL}}[\%]+\mathrm{ARC}_{\mathrm{ACSL}}[\%]^{*} \\
& * \text { when ACSL is present }
\end{aligned}
$$

a) Area reduction coefficient of the STSL (ARC $\left.\mathrm{STSL}_{\mathrm{S}}\right)$ (Figure 1A):

$$
\mathrm{ARC}_{\mathrm{STSL}}[\%]=(\mathrm{aSTSL} / \mathrm{aSSN}) \times 100
$$

b) Area reduction coefficient of the ACSL (ARC $\mathrm{ACSL}_{\mathrm{N}}$ ) (Figure 1B):

$$
\mathrm{ARC}_{\mathrm{ACSL}}[\%]=(\mathrm{aACSL} / \mathrm{aSSN}) \times 100
$$
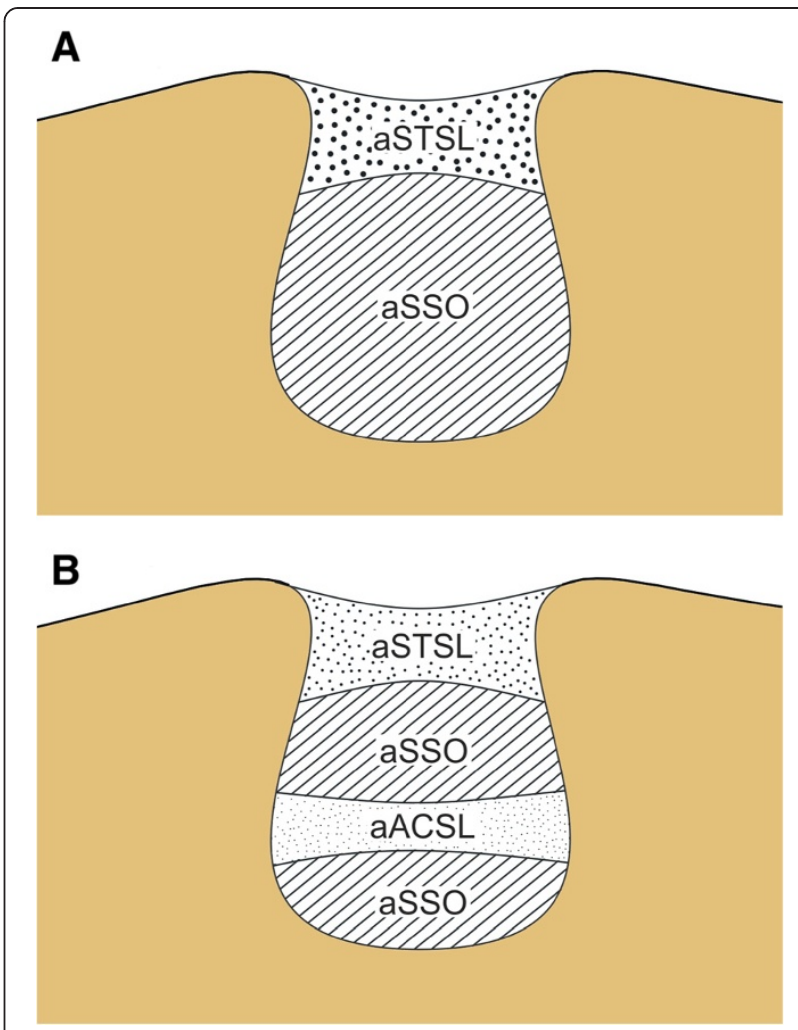

Figure 1 Schematic representation of the measurements of the areas in the suprascapular region: aSTSL - area of the superior transverse scapular ligament; aACSL - area of the anterior coracoscapular ligament; aSSO - area of the suprascapular opening. $\mathbf{A}$ - specimens without ACSL. B - specimens with ACSL.

$$
\begin{gathered}
\mathrm{aSSN}=\mathrm{aSTSL}+\mathrm{aACSL}^{*}+\mathrm{aSSO} \\
* \text { when ACSL present }
\end{gathered}
$$

aSSN - area of the suprascapular notch - area limited by the superior border of the STSL and bony border of the SSN.

aSTSL - area of the superior transverse scapular ligament - area limited by the superior and inferior border of the STSL and bony borders of the SSN at the line of proximal and distal attachment of the STSL.

aACSL - area of the anterior coracoscapular ligament - area limited by the superior and inferior border of the ACSL and bony borders of the SSN at the line of proximal and distal attachment of the ACSL.

aSSO - area of the suprascapular opening - area of the suprascapular notch that is not occupied by the STSL and/or ACSL. When the ACSL is absent, the aSSO is identical with that of the SN passage (Figure 1A). However, when the ACSL is present, it divides the aSSO into the $\mathrm{SN}$ passage 


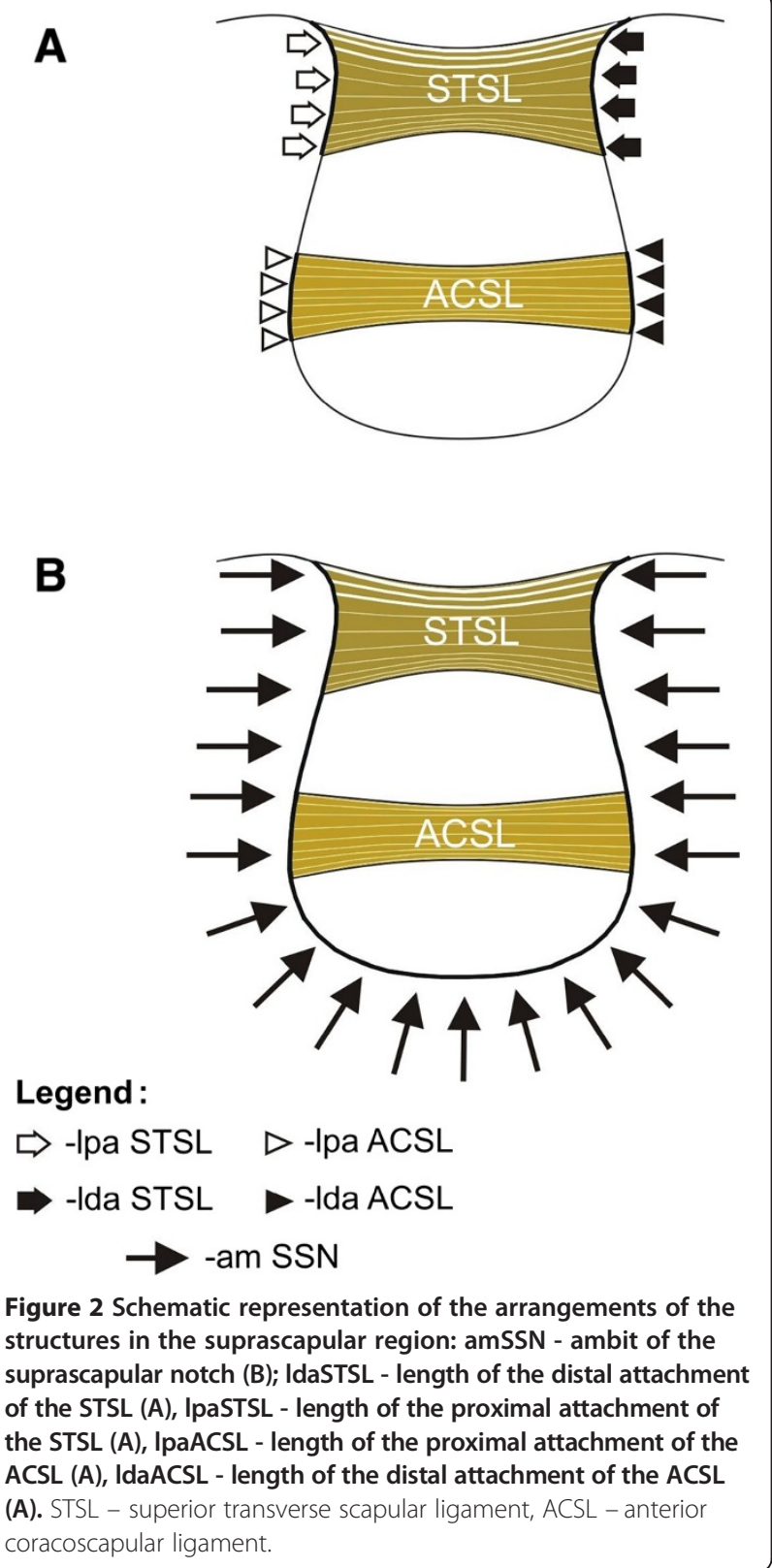

and the opening between its lower border and bony border of the SSN (Figure 1B).

2. The ambit occupation coefficient (AOC), calculated according to the following formula (Figure 2):

$$
\mathrm{AOC}[\%]=\mathrm{AOC}_{\mathrm{STSL}}[\%]+\mathrm{AOC}_{\mathrm{ACSL}}[\%]^{*}
$$

* when ACSL present

a) The ambit occupation coefficient of the STSL $\left(\mathrm{AOC}_{\mathrm{STSL}}\right)$

$$
\mathrm{AOC}_{\text {STSL }}[\%]=[(\text { ldaSTSL }+ \text { lpaSTSL }) / \mathrm{amSSN}] \times 100
$$

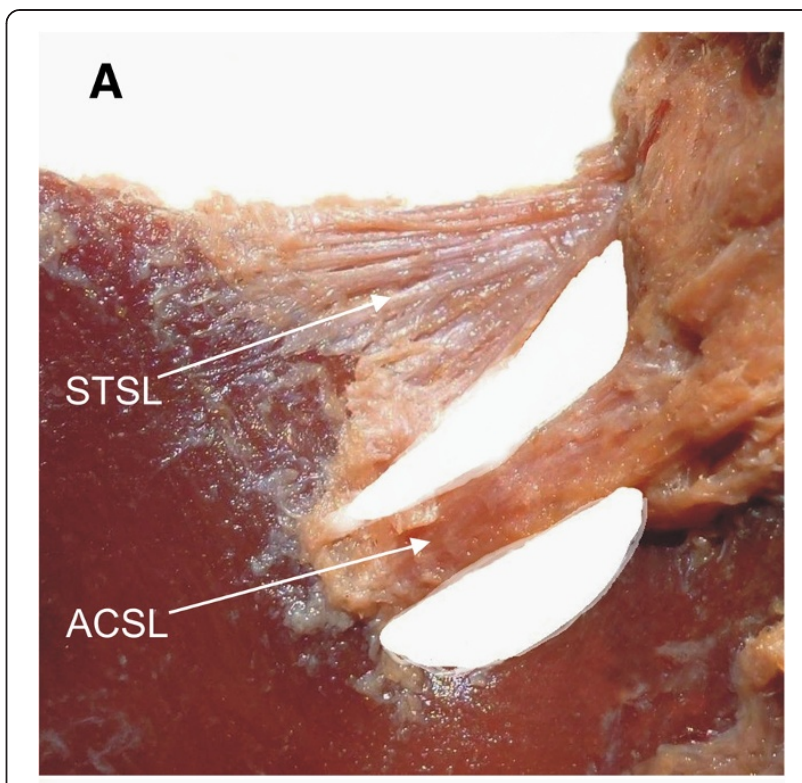

B

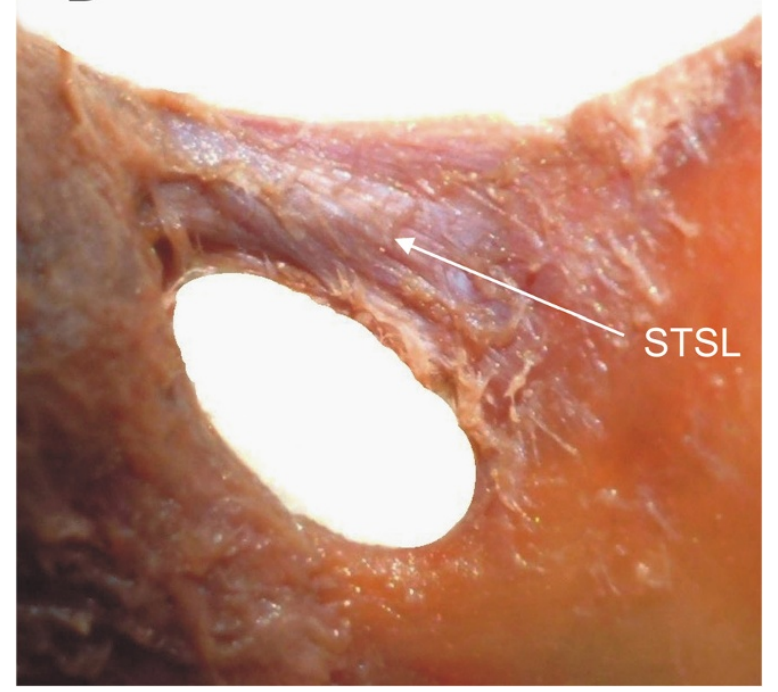

Figure 3 Structures of the suprascapular region: STSL - superior transverse scapular ligament, ACSL - anterior coracoscapular ligament. A - fan-shaped STSL. B - band-shaped STSL.

b). The ambit occupation coefficient of the ACSL $\left(\mathrm{AOC}_{\mathrm{ACSL}}\right)$

$\mathrm{AOC}_{\mathrm{ACSL}}[\%]=[(\mathrm{ldaACSL}+\mathrm{lpaACSL}) / \mathrm{amSSN}] \times 100$

amSSN - ambit of the suprascapular notch - length of the bony border of the SSN.

ldaSTSL - length of the distal attachment of the STSL - length of the bony border adjacent to the distal attachment of the STSL.

lpaSTSL - length of the proximal attachment of the STSL - length of the bony border adjacent to the proximal attachment of the STSL. 
ldaACSL - length of the distal attachment of the ACSL - length of the bony border adjacent to the distal attachment of the ACSL.

lpaACSL - length of the proximal attachment of the ACSL - length of the bony border adjacent to the distal attachment of the ACSL.

All parameters give information about the contribution of the different types of SSN and STSL, as well as the presence of the ACSL, to the total area reduction of the SN passage. The normality of data distribution was tested with the Shapiro-Wilk test. The difference between the two types of STSL with regard to ARC, AOC and SN passage area was evaluated by the Mann-Whitney test. The comparison of those parameters between SSN types was tested with the Kruskal-Wallis one-way analysis of variance with dedicated post-hoc analysis. Correlations were evaluated by means of the Spearman's rank correlation coefficient. For the statistical analysis, $\mathrm{p}<0.05$ was considered significant.

\section{Results}

In all cases, the SN travelled below the STSL together with the suprascapular vein. The mean cross-sectional area of the suprascapular nerve was found to be 3.43 $\mathrm{mm}^{2} \pm 0.42 \mathrm{~mm}^{2}$ (mean \pm standard deviation). The mean diameters of the suprascapular artery and vein were 2.17 $\mathrm{mm}(\mathrm{SD}=0.5 \mathrm{~mm})$ and $3.52 \mathrm{~mm}(\mathrm{SD}=0.6 \mathrm{~mm})$, respectively. In 4 specimens, the suprascapular artery travelled below the STSL. An ACSL was present in 52 specimens (Figure 3A).

\section{Area reduction coefficient (ARC)}

The mean value for the ARC was $72.6 \% \pm 12 \%$ (mean \pm standard deviation), being $71.6 \% \pm 26.4 \%, 9.6 \% \pm 7.6 \%$ and $32 \% \pm 21.1 \%$ for the aSTSL, aACSL and aSSO, respectively

Table 1 Characteristics of ARC associated parameters according to STSL and SSN types

\begin{tabular}{|c|c|c|c|c|c|c|c|c|c|c|c|c|}
\hline \multirow{2}{*}{\multicolumn{2}{|c|}{ Parameters of area reduction }} & \multicolumn{2}{|c|}{ STSL } & \multicolumn{9}{|c|}{ SSN type } \\
\hline & & Fan-type & $\overline{\text { Band-type }}$ & IA & IB & IC & II & IIIA & IIIB & IIIC & IV & $\mathrm{v}$ \\
\hline \multirow[t]{2}{*}{ Number } & & 56 & 44 & 2 & 1 & 2 & 11 & 6 & 13 & 59 & 3 & 3 \\
\hline & Mean & 119.1 & 93.66 & 140.7 & 240 & 109.75 & 100.1 & 111.4 & 130.1 & 103.35 & 106.71 & 43.2 \\
\hline \multirow[t]{3}{*}{$\mathrm{aSSN}\left[\mathrm{mm}^{2}\right]$} & SD & 42.3 & 31.17 & 76.01 & - & 7.42 & 27.7 & 28.87 & 47.98 & 34.02 & 17.62 & 29 \\
\hline & $p$ & & 032 & & & & & 0.0556 & & & & \\
\hline & Mean & 76.8 & 65.3 & 94.3 & 172 & 78.1 & 67.9 & 77.6 & 78.23 & 68.38 & 91.37 & 34.6 \\
\hline \multirow[t]{3}{*}{ aSTSL $\left[\mathrm{mm}^{2}\right]$} & SD & 28.12 & 23 & 10.3 & - & 17.68 & 26.09 & 13.36 & 31.55 & 22.52 & 6.86 & 24.23 \\
\hline & $p$ & & 887 & & & & & $0.0261^{t}$ & & & & \\
\hline & Mean & 9.03 & 10.12 & 18.2 & - & 11.3 & 11.59 & - & 11.39 & 9.2 & - & - \\
\hline \multirow[t]{3}{*}{$\mathrm{aACSL}\left[\mathrm{mm}^{2}\right]^{*}$} & SD & 8.69 & 6.63 & - & - & 1.84 & 7.31 & - & 9.02 & 7.32 & - & - \\
\hline & $p$ & & 996 & & & & & 0.3423 & & & & \\
\hline & Mean & 38.56 & 23.9 & 41.95 & 64 & 21.85 & 26.89 & 32.17 & 47.21 & 31.1 & 13.17 & 9.1 \\
\hline \multirow[t]{3}{*}{$\mathrm{aSSO}\left[\mathrm{mm}^{2}\right]$} & SD & 22.32 & 16.33 & 59.3 & - & 9.4 & 14.5 & 18.97 & 28.67 & 17.96 & 8.58 & 6.99 \\
\hline & $p$ & & 004 & & & & & 0.1395 & & & & \\
\hline & Mean & 36.84 & 20.86 & 36.5 & 64 & 7.8 & 22.78 & 32.17 & 43.8 & 29.5 & 13.17 & 7.8 \\
\hline \multirow[t]{3}{*}{ SN passage area $\left[\mathrm{mm}^{2}\right]$} & SD & 21.89 & 15.46 & 51.2 & - & 3.96 & 13.22 & 18.97 & 30.6 & 17.2 & 8.58 & 5.35 \\
\hline & $p$ & & 017 & & & & & $0.0306^{\dagger}$ & & & & \\
\hline & Mean & 65.3 & 70.9 & 76.1 & 71.7 & 70.8 & 67.3 & 71.6 & 61.1 & 67.2 & 86.5 & 74.2 \\
\hline \multirow[t]{3}{*}{$\mathrm{ARC}_{\text {STSL }}[\%]$} & SD & 10.7 & 13.8 & 33.8 & - & 11.3 & 13.4 & 12.8 & 11.3 & 11.5 & 8.3 & 1.1 \\
\hline & $p$ & & 274 & & & & & 0.1526 & & & & \\
\hline & Mean & 7.9 & 10.2 & 9.4 & - & 10.3 & 12.6 & - & 10.5 & 8.5 & - & - \\
\hline \multirow[t]{3}{*}{$\mathrm{ARC}_{\mathrm{ACSL}}[\%]^{*}$} & SD & 8.2 & 7 & - & - & 1 & 8.5 & - & 8.3 & 7.3 & - & - \\
\hline & $p$ & & 947 & & & & & $0.0489^{\dagger}$ & & & & \\
\hline & Mean & 68.6 & 77.6 & 80.8 & 71.7 & 81.0 & 78.1 & 71.6 & 67.6 & 70.8 & 86.5 & 86.6 \\
\hline \multirow[t]{2}{*}{ ARC [\%] } & SD & 10.5 & 12.5 & 27.2 & - & 12.3 & 14.3 & 12.8 & 11.3 & 10.8 & 8.3 & 11.2 \\
\hline & $p$ & \multicolumn{2}{|c|}{0.00002} & & & & & 0.0966 & & & & \\
\hline
\end{tabular}


(Table 1). The area reduction coefficient was significantly correlated with the ambit occupation coefficient $(\mathrm{R}=0.6855 ; \mathrm{p}<0.0001)$ (Figure $4 \mathrm{~A})$ and with $\mathrm{SN}$ passage area $(\mathrm{R}=-0.7555 ; \mathrm{p}<0.0001)$ (Figure $4 \mathrm{~B})$. The correlation with SN passage area was stronger in band-shaped STSL $(\mathrm{R}=-0.7064 ; \mathrm{p}<0.0001)$ than in the fan-shaped type $(\mathrm{R}=-0.6347 ; \mathrm{p}<0.0001)$. The ARC values for fan-shaped (Figure 3A) and band-shaped (Figure 3B) STSL types were estimated to be $65.3 \%$ and $70.9 \%$, respectively (Table 1 ), which was significantly different $(\mathrm{p}=0.0274)$. Furthermore, $\mathrm{ARC}_{\mathrm{STSL}}$ correlated inversely with the $\mathrm{ARC}_{\mathrm{ACSL}}$ $(\mathrm{R}=-0.306 ; \mathrm{p}=0.0022)$. This correlation was stronger in band-shaped STSL $(\mathrm{R}=-0.4753 ; \mathrm{p}=0.0011)$ than in the fan-shaped type $(\mathrm{R}=-0.3155 ; \mathrm{p}=0.0201)$. Table 1 presents the ARC values evaluated within different types of SSN and STSL in detail.

\section{Ambit occupation coefficient (AOC)}

The value of the AOC was $61.2 \% \pm 10 \%$. The ambit occupation coefficient for the STSL was $56.8 \% \pm 9.9 \%$ and for the ACSL $9.1 \% \pm 7.5 \%$. Those parameters did not correlate with each other. However, there was a significant correlation between the AOC and SN passage area $(R=-0.5609$; $\mathrm{p}<0.0001)$. Also, with respect to STSL type, correlation with the AOC was stronger in fan-shaped STSLs $(\mathrm{R}=$ 0.7331; $\mathrm{p}<0.0001)$ than the band-shaped type $(\mathrm{R}=0.6497$;
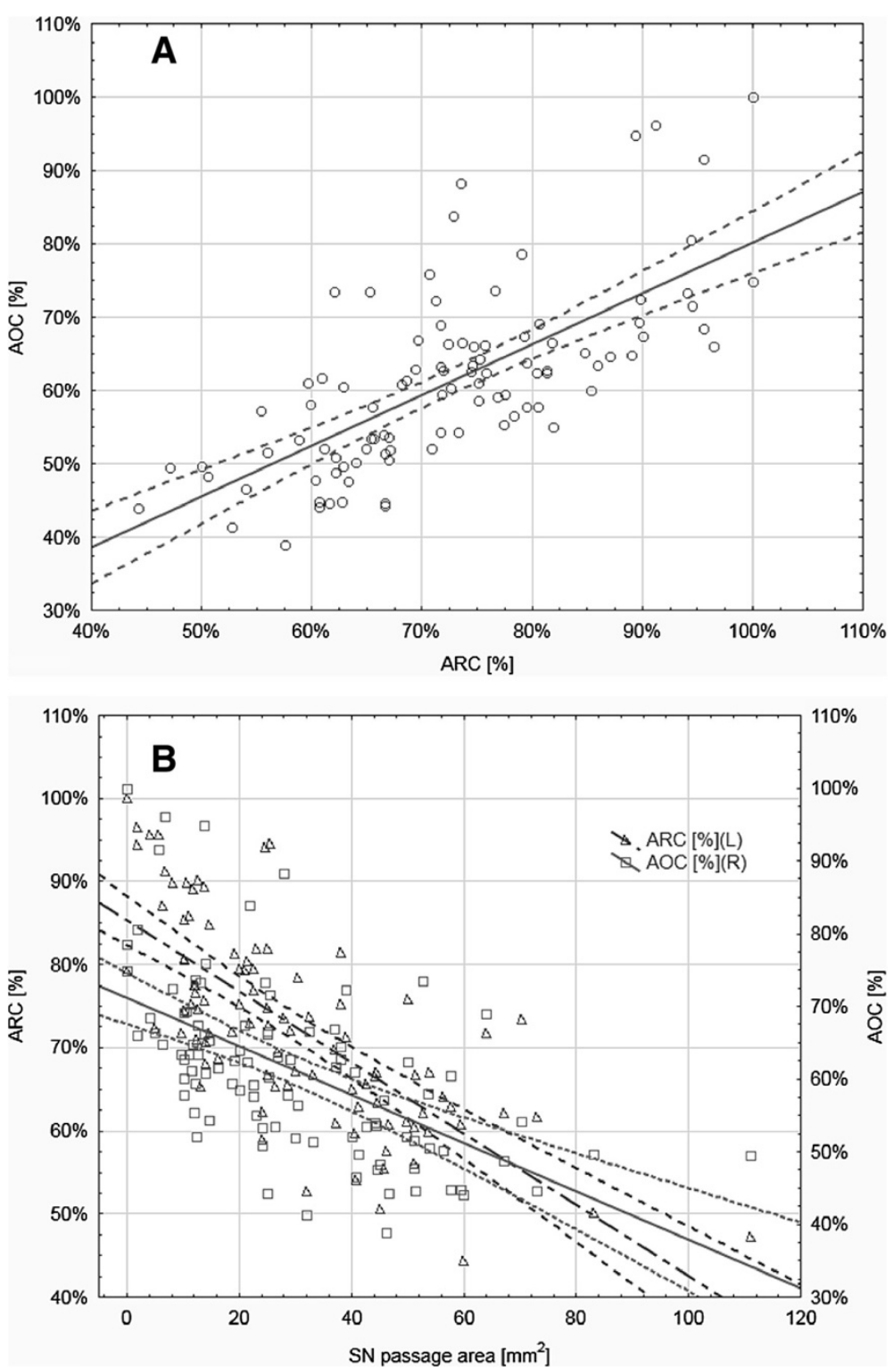

Figure 4 Correlation plots between area reduction coefficient (ARC) and ambit occupation coefficient (AOC) (A) and between SN passage area and both parameters (B). 
$\mathrm{p}<0.0001)$. Also $\mathrm{AOC}_{\mathrm{ACSL}}$ significantly correlated with SN passage area $(R=-0.2658 ; p=0.0082)$ but not as strongly as in the case of the AOC STSL $(\mathrm{R}=-0.5609$; $\mathrm{p}<0.0001)$. Differences in ambit parameters between STSL and SSN types are presented in Table 2.

\section{Discussion}

Structures surrounding the SN make it vulnerable to injury and compression by many different mechanisms. Direct compression caused by a mass in the SSN region (e.g. ganglion/labral cyst, tumour) [10,11], repetitive irritation in overhead activities caused by the "sling effect" [7], continuous nerve traction following a rotator cuff tear $[12,13]$ or an inflammation process (e.g.viral neuritis) [14] can all lead to SN neuropathy. Anatomical variations of structures creating the osteo-fibrous tunnel for the SN can increase the risk of this pathology by constricting the nerve passage. Although it has been hypothesized that $\mathrm{SN}$ neuropathy is more likely to occur in patients with a narrow, V-shaped SSN, no direct correlation between SSN type and SN injury has been confirmed. Based on a cadaveric study, Ürgüden et al. [15] suggest that Rangachery type IV and V of the SSN may increase the risk of iatrogenic SN injury during rotator cuff tear repair, but no clinical data supports this theory. Furthermore, as shown in this study, the area of the SN passage does not differ between any particular type of SSN. Hence, it seems to be more important to evaluate the area for SN passage than just the type of SSN [10].

However, it is difficult to evaluate this area by means of imaging modalities. Magnetic resonance imaging reveals morphological changes in denervated muscles such as muscle oedema, muscle atrophy or fatty changes, but is limited with regard to the aetiology of nerve entrapment when no mass or cyst is affecting the nerve $[12,16,17]$. Furthermore, due to the position of the scapula, which is tilted anteriorly and rotated internally, standard shoulder MRI examination protocol does not allow for proper visualisation of the nerve passage. Even with an adjusted protocol, the exact evaluation of such a small structure might be challenging. Although 3-Tesla scanners support better resolution [18], 1.5-Tesla scanners are still more common, and the application of a higher magnetic field does not guarantee that the suprascapular ligament, which is usually $1-2 \mathrm{~mm}$ thick, will be visualised in any of the scans.

The present study uses the newest classifications for both the SSN [9] and STSL [6]. This approach is simple, reproducible, and based on specific geometrical measurements that clearly distinguish each type, which is not the case for many existing schemes.

The bony border of the SSN can be visualised by classical radiography [12] or by CT scan [19]. However, no certain information about the STSL can be obtained, even in the case of patients with complete STSL ossification. The frequency of complete calcification varies between populations: It has been reported in $5.5 \%-12.5 \%$ of cases $[5,20]$. Although STSL ossification is a well-known risk factor of SN neuropathy [10], its presence was not included in this study as these parameters focus on the area of the nerve passage. Since the ossified ligament is an independent risk factor, its presence should always arouse suspicion of nerve irritation not pending on the tunnel area.

The majority of STSLs are non-ossified, and these can be visualised and evaluated by means of sonography [21-23]. According to the presented data, recognition of STSL type can have clinical implications, because the

Table 2 Characteristic of AOC associated parameters according to STSL and SSN types

\begin{tabular}{|c|c|c|c|c|c|c|c|c|c|c|c|c|}
\hline \multirow{2}{*}{$\begin{array}{l}\text { Parameters of } \\
\text { area reduction }\end{array}$} & & \multicolumn{2}{|c|}{ STSL } & \multicolumn{9}{|c|}{ SSN type } \\
\hline & & Fan-type & Band-type & IA & IB & IC & II & IIIA & IIIB & IIIC & IV & v \\
\hline \multirow[t]{2}{*}{ Number } & & 56 & 44 & 2 & 1 & 2 & 11 & 6 & 13 & 59 & 3 & 3 \\
\hline & Mean & 31.5 & 28.2 & 34.1 & 47 & 35.1 & 28.65 & 30.18 & 33.05 & 29.19 & 36.5 & 19.23 \\
\hline \multirow[t]{3}{*}{ amSSN [mm] } & SD & 5.95 & 5.65 & 4.1 & - & 0.85 & 5.64 & 5.42 & 7.7 & 4.89 & 1.8 & 7.64 \\
\hline & $\mathrm{p}$ & \multicolumn{2}{|c|}{0.0061} & \multicolumn{9}{|c|}{$0.0028^{+}$} \\
\hline & Mean & 55.5 & 58.3 & 59.7 & 60.4 & 59.2 & 55.3 & 61.1 & 52.2 & 56.7 & 67.1 & 64.5 \\
\hline \multirow[t]{3}{*}{$\mathrm{AOC}_{\text {STSL }}[\%]$} & SD & 7.9 & 11.9 & 21.4 & - & 2.2 & 10.8 & 10.4 & 8.7 & 10.1 & 1.6 & 1.7 \\
\hline & $\mathrm{p}$ & \multicolumn{2}{|c|}{0.1797} & \multicolumn{9}{|c|}{0.0746} \\
\hline & Mean & 4.4 & 4.6 & 7.5 & 6.4 & 8.6 & 8.6 & 8.3 & 5.2 & 3.4 & - & - \\
\hline \multirow[t]{3}{*}{$\mathrm{AOC}_{\mathrm{ACSL}}[\%]^{*}$} & SD & 7.7 & 5.9 & 6.3 & - & 4.2 & 7.1 & 10.9 & 5.5 & 6.8 & - & - \\
\hline & $p$ & \multicolumn{2}{|c|}{0.8707} & \multicolumn{9}{|c|}{0.1491} \\
\hline & Mean & 59.9 & 62.9 & 67.3 & 66.8 & 67.8 & 63.9 & 69.5 & 57.4 & 60.1 & 67.1 & 64.5 \\
\hline \multirow[t]{2}{*}{$\mathrm{AOC}[\%]$} & SD & 11.6 & 12.6 & 27.7 & - & 2.0 & 13.9 & 18.2 & 11.1 & 11.8 & 1.6 & 1.7 \\
\hline & $p$ & \multicolumn{2}{|c|}{0.2331} & \multicolumn{9}{|c|}{$0.0059^{\dagger}$} \\
\hline
\end{tabular}


SN passage area is known to be significantly decreased in the case of band-shaped STSL types. Although the anterior coracoscapular ligament has also been suggested as a risk factor of SN neuropathy, only ARC $\mathrm{ATSL}_{\mathrm{ST}}$ and $\mathrm{ARC}$, but not $\mathrm{ARC}_{\mathrm{ACSL}}$ were found to be significantly increased in band-shaped STSLs. Furthermore, an inverse correlation exists between $\mathrm{ARC}_{S T S L}$ and the $\mathrm{ARC}_{\mathrm{ACSL}}$ but no correlation between $\mathrm{AOC}_{\mathrm{STSL}}$ and the $\mathrm{AOC}_{\mathrm{ACSL}}$. All the above suggest that the size of the ACSL relies to some extent on the size of the STSL, however, the STSL is the main factor constricting the SN passage area.

The proposed parameters have some limitations. Contrary to the ARC, calculation of the AOC does not require tools for area evaluation but only measurement of curves along the border of the SSN. However, this parameter does not take into account the curved inferior (STSL) or superior (ACSL) borders of the ligaments. Thus, AOC measurement can overestimate the predicted risk in ligaments with distinctly curved borders. On the other hand, the SSN ambit below the ACSL is not included in the formula, which may cause the risk to be underestimated.

Another factor that can bias the accuracy of the proposed parameters concerns the presence of an artery in the osteo-fibrous tunnel that usually houses only the nerve and vein. Anomalies of artery alignment were observed in $4 \%$ of analysed cases. This rate is higher than the $2.5 \%$ reported by Tubbs et al. [20] and $3 \%$ by Reineck et al. [24], but lower than the $10.9 \%$ reported by Yang et al. [25]. It was suggested that when the artery neighbours the nerve directly, it might exert blood pressure on the more fragile nerve, causing microtrauma to the nerve, ultimately resulting in neuropathy [20]. Also the varix of the suprascapular vein, which has only been reported at the level of the spinoglenoid notch, might reduce the free area for the nerve. However, due to difficulties in clinical evaluation of those small vessels and their unconfirmed aetiological status, they were not considered when calculating the parameters.

\section{Conclusion}

Both the ARC and the AOC are well correlated with the SN passage area, and so might be used in the evaluation of the risk of SN neuropathy, without direct visualisation of the nerve passage. Furthermore, the ARC is characterised by lower standard deviation with respect to the SN passage area. Hence, due to the difficulty of passage area evaluation, and the limitations associated with AOC, ARC seems to be the most relevant and reliable parameter for evaluating the constellation of anatomical risk factors of SN neuropathy. The usefulness of proposed parameters should be further tested under clinical conditions.

\section{Competing interests}

The authors declare that they have no competing interest.

\section{Authors' contributions}

MPodgórski - study design, data collection, data interpretation, manuscript preparation, literature search, figure preparation. MT - study design, data interpretation, manuscript preparation, literature search, fund collection. MS - data interpretation, manuscript preparation, literature search. PG - data interpretation, literature search. LS - study design, data interpretation, manuscript preparation. MPolguj - study design, data collection, data interpretation, manuscript preparation, figure preparation, fund collection. All authors read and approved the final manuscript.

\section{Acknowledgments}

The authors thank the donors and families of the cadavers used for this research.

\section{Author details}

${ }^{1}$ Department of Angiology, Chair of Anatomy, Medical University of Łódź, Narutowicza 60, Łódź 90-136, Poland. ²Department of Normal and Clinical Anatomy, Chair of Anatomy, Medical University of Łódź, Łódź, Poland. ${ }^{3}$ Clinic of Orthopaedic and Pediatric Orthopaedics, Medical University of Łódź, Łódź, Poland. ${ }^{4}$ Department of Radiology, Medical University of Łódź, Łódź, Poland.

Received: 20 October 2013 Accepted: 11 November 2014 Published: 25 November 2014

\section{References}

1. Bochenek A, Reicher M: Human Anatomy, Volume III. Warsaw: Wydawnictwo Lekarskie PZWL; 2006:241-242.

2. Boykin RE, Friedman DJ, Higgins LD, Warner JJ: Suprascapular neuropathy. J Bone Joint Surg Am 2010, 92:2348-2364. doi:10.2106/JBJS.I.01743.

3. Pecina $M$ : Who really first described and explained the suprascapular nerve entrapment syndrome? J Bone Joint Surg Am 2001, 83-A:1273-1274.

4. Albino P, Carbone S, Candela V, Arceri V, Vestri AR, Gumina S: Morphometry of the suprascapular notch: correlation with scapular dimensions and clinical relevance. BMC Musculoskelet Disord 2013, 14:172. doi:10.1186/1471-2474-14-172.

5. Bayramoglu A, Demiryurek D, Tuccar E, Erbil M, Aldur MM, Tetik O, Doral MN: Variations in anatomy at the suprascapular notch possibly causing suprascapular nerve entrapment: an anatomical study. Knee Surg Sports Traumatol Arthrosc 2003, 11:393-398. doi:10.1007/s00167-003-0378-3.

6. Polguj M, Jędrzejewski K, Podgórski M, Majos A, Topol M: A proposal for classification of the superior transverse scapular ligament: variable morphology and its potential influence on suprascapular nerve entrapment. J Shoulder Elbow Surg 2013, 22:1265-1273. doi:10.1016/j.jse.2012.11.017.

7. Rengachary SS, Burr D, Lucas S, Hassanein KM, Mohn MP, Matzke H: Suprascapular entrapment neuropathy: a clinical, anatomical, and comparative study. Part 1: Clinical study. Neurosurgery 1979, 5:441-446.

8. Avery BW, Pilon FM, Barclay JK: Anterior coracoscapular ligament and suprascapular nerve entrapment. Clin Anat 2002, 15:383-386. doi:10.1002/ca.10058.

9. Polguj M, Jędrzejewski K, Podgórski M, Topol M: Morphometric study of the suprascapular notch - proposal of classification. Surg Radiol Anat 2011, 33:781-787. doi:10.1007/s00276-011-0821-y.

10. Cummins CA, Messer TM, Nuber GW: Suprascapular nerve entrapment. J Bone Joint Surg 2000, 82-A:415-424.

11. Sherman PM, Sanders TG, De Lone DR: A benign soft tissue mass simulating a glenoid labral cyst on unenhanced magnetic resonance imaging. Mil Med 2004, 169:376-378.

12. Shi LL, Freehill MT, Yannopoulos P, Warner JJ: Suprascapular nerve: is it important in cuff pathology? Adv Orthop 2012, 2012:516985. doi:10.1155/ 2012/516985.

13. Massimini DF, Singh A, Wells JH, Li G, Warner JJ: Suprascapular nerve anatomy during shoulder motion: a cadaveric proof of concept study with implications for neurogenic shoulder pain. J Shoulder Elbow Surg 2013, 22:463-470. doi:10.1016/j.jse.2012.04.018.

14. Antoniou J, Tae SK, Williams GR, Bird S, Ramsey ML, lannotti JP: Suprascapular neuropathy. Variability in the diagnosis, treatment, and outcome. Clin Orthop Relat Res 2001, 386:131-138.

15. Urgüden $M$, Ozdemir $H$, Dönmez B, Bilbaşar $H$, Oğuz N: Is there any effect of suprascapular notch type in iatrogenic suprascapular nerve lesions? An anatomical study. Knee Surg Sports Traumatol Arthrosc 2004, 12:241-245. 
16. O'Connor EE, Dixon LB, Peabody T, Stacy GS: MRI of cystic and soft-tissue masses of the shoulder joint. AJR Am J Roentgenol 2004, 183:39-47.

17. Ludig T, Walter F, Chapuis D, Molé D, Roland J, Blum A: MR imaging evaluation of suprascapular nerve entrapment. Eur Radiol 2001, 11:2161-2169.

18. Chalian M, Faridian-Aragh N, Soldatos T, Batra K, Belzberg AJ, Williams EH, Carrino JA, Chhabra A: High-resolution 3T MR neurography of suprascapular neuropathy. Acad Radiol 2011, 18:1049-1059. doi:10.1016/j.acra.2011.03.003.

19. Moen TC, Babatunde OM, Hsu SH, Ahmad CS, Levine WN: Suprascapular neuropathy: what does the literature show? J Shoulder Elbow Surg 2012, 21:835-846. doi:10.1016/j.jse.2011.11.033

20. Tubbs RS, Smyth MD, Salter G, Oakes WJ: Anomalous traversement of the suprascapular artery through the suprascapular notch: a possible mechanism for undiagnosed shoulder pain? Med Sci Monit 2003, 9:BR116-BR119.

21. Martinoli C, Bianchi S, Pugliese F, Bacigalupo L, Gauglio C, Valle M, Derchi LE: Sonography of entrapment neuropathies in the upper limb (wrist excluded). J Clin Ultrasound 2004, 32:438-450.

22. Moriggl B: Fundamentals, possibilities and limitations of sonography of osteofibrous tunnels in the shoulder area. Ann Anat 1997a, 179:355-373.

23. Moriggl B: Fundamentals, possibilities and limitations of sonography of osteofibrous tunnels in the shoulder area. Ann Anat 1997b, 179:375-392.

24. Reineck JR, Krishnan SG: Subligamentous suprascapular artery encountered during arthroscopic suprascapular nerve release: a report of three cases. J Shoulder Elbow Surg 2009, 18:e1-e3. doi:10.1016/j.jse.2008.08.007.

25. Yang HJ, Gil YC, Jin JD, Ahn SV, Lee HY: Topographical anatomy of the suprascapular nerve and vessels at the suprascapular notch. Clin Anat 2012, 25:359-365.

doi:10.1186/1471-2474-15-396

Cite this article as: Podgórski et al:: New parameters describing morphological variations in the suprascapular notch region as potential predictors of suprascapular nerve entrapment. BMC Musculoskeletal Disorders 2014 15:396.

\section{Submit your next manuscript to BioMed Central and take full advantage of:}

- Convenient online submission

- Thorough peer review

- No space constraints or color figure charges

- Immediate publication on acceptance

- Inclusion in PubMed, CAS, Scopus and Google Scholar

- Research which is freely available for redistribution 